\title{
O problema da restituição em Tomás de Aquino
}

\author{
VITOR LEANDRO KAIZER \\ Universidade do Vale do Rio dos Sinos
}

DOI: $10.36446 /$ rlf2020196

Resumo: No presente artigo tratou-se sobre a Questão 62 da Secunda Secundae, da Suma Teológica de Tomás de Aquino. O objetivo principal foi apresentar e discutir a perspectiva do filósofo sobre o problema da restituição. A relevância desta pesquisa está no fato de que o tema tratado apresenta consideráveis discussões acerca de problemas extremamente atuais; sobretudo, porque a restituição, segundo Tomás, visa restabelecer um estado de harmonia social e individual e, portanto, é essencial ao bem estar social. Sendo assim, apresentaram-se os oito artigos pertinentes à restituição e se trabalhou no sentido de fazer aproximações entre as principais ideias expostas. Deste modo, foi possível chegar à conclusão de que o tratamento que o filósofo dá ao problema provém de uma análise racional sobre o imperativo da justiça para o convívio social e que a restituição é um meio de estabelecer novamente o equilíbrio social e o bem estar individual quando a justiça tenha sido ferida. 
Palavras-chave: filosofia, Tomás de Aquino, justiça, direito, restituição.

\title{
The Problem of Restitution in Thomas Aquinas
}

\begin{abstract}
This article deals with Question 62 of the Secunda Secundae, of the Theological Sum of Thomas Aquinas. The main objective was to present and discuss the philosopher's perspective on the problem of restitution. The relevance of this research lies in the fact that the subject treated presents considerable discussions about extremely current problems; above all, because the restitution, according to Thomas, aims to reestablish a state of social and individual harmony and, therefore, is essential to social welfare. Thus, the eight articles pertaining to the restitution were presented and efforts were made to approximate the main ideas presented. In this way, it was possible to conclude that the philosopher's treatment of the problem comes from a rational analysis of the imperative of justice for social life and that restitution is a means of reestablishing social balance and individual well-being when justice has been wounded.
\end{abstract}

Key-words: philosophy, Thomas Aquinas, justice, right, refund.

\section{A justiça em Tomás de Aquino}

$\mathrm{O}$ problema da justiça é um assunto frequente em Tomás de Aquino, de modo que essa constância representa uma tentativa de esclarecimento do conceito. A palavra justiça recebeu usos e significados amplos no curso histórico das sociedades, mas, apesar disso, caracteriza-se como uma espécie de primazia pela correção e equidade. O próprio símbolo da justiça em ação na balança de dois pratos representa a ideia da severidade na aferição de duas medidas e a constatação lógica de um único resultado. Portanto, justiça é um estado de coisas e relações equilibradas.

Sendo a justiça um atributo lógico e necessário para a preservação da harmonia em meio à diversidade do conjunto que impõe a vida em sociedade, Tomás identificará nela o fator indispensável para a regulação da vida social do homem. Neste sentido, González entende que

[...] se o homem fosse um ser solitário, se não houvesse outros homens, não haveria necessidade de ordenar ações pela virtude da justiça, cuja missão é justamente regular as relações com os outros - seja o outro em geral (no caso 
de justiça legal) ou o outro indivíduo (no caso de justiça especial) (González 2016: 13, tradução nossa).

Se o homem é um ser que vive em sociedade, então certa regulação das suas ações no âmbito social se apresenta como medida essencial para a preservação desse equilíbrio. Tomás compreende a justiça como um imperativo para a conservação da vida em sociedade, pois sem ela não seria possível a consecução, ou a sustentação, de um estado harmônico. Por esta razão, Culleton afirma que,

a tradição tomista entende que os homens estão unidos na sociedade para suprir suas necessidades e para beneficiar a vida em sociedade e nenhum deles tem o direito de abusar dos outros, que essa pessoa iria contra a própria lógica que justifica a constituição da sociedade, que é o favorecimento mútuo e a satisfação das necessidades. A vida em sociedade exige a equivalência (Culleton 2017: 252).

Essa equivalência entre os indivíduos que compõem o corpo social emana do entendimento de que justo é aquilo que pertence a determinado sujeito, ao passo que injusto é aquilo que não lhe pertence. Portanto, para o bem coletivo, a justiça deve ser vista como um ideal capaz de guiar, orientar e respaldar as atitudes dos indivíduos na consecução da harmonia social.

Na obra Suma Teológica, Tomás de Aquino desenvolve essa problemática partindo do princípio de que a justiça seja uma virtude do ser humano (Cf. Tratado das virtudes em geral: ST, I-II, Q 55-67). Neste sentido, compreende que

uma virtude pode ser considerada, na sua espécie, maior ou menor, absoluta ou relativamente falando. É absolutamente maior aquela em que esplende um maior bem racional [...]. E a esta luz, a justiça tem preexcelência sobre todas as virtudes morais, como sendo mais próxima da razão; o que claramente se manifesta tanto pelo seu sujeito como pelo seu objeto. Pois, o sujeito da justiça é a vontade, que é o apetite racional, segundo já foi claramente estabelecido. O objeto ou matéria da justiça são os atos pelos quais o homem tem relação, não só consigo mesmo, mas também com outrem. Por onde, a justiça é a preclaríssima das virtudes [...] (Tomás, ST I-II, Q 66, A 4, resp.).

Na percepção do filósofo, a justiça se reveste de um atributo lógico-moral que se manifesta tanto como uma vontade racional condutora dos atos dos seres pensantes - por conseguinte, dos seres virtuosos-, como também em fatos que refletem, por correspondência à ponderação que cada 
qual exerce em sua própria consciência, o maior ou menor grau de ativação dessa mesma vontade racional. Assim, Tomás entende que a justiça seja a virtude de maior excelência, pois é ela quem produz os maiores beneficios à razão que, por sua vez, traduz-se na harmonia social.

Portanto, em princípio, o objeto da vontade contém todos e cada um dos bens particulares que se referem à consistência de nossa natureza e, em suma, ao bem humano. Ainda assim, $[. .$.$] na prática, a realização do bem humano$ significa informar cada ação particular com uma razão particular. (González 2016: 17-18, tradução nossa).

Sendo os efeitos da justiça benéficos a todos os indivíduos que dela participam e em cuja virtude maior está a de guiar os atos humanos no âmbito do convívio e das relações sociais na busca pela conservação do equilíbrio, então o contínuo esforço pela execução de ações justas, entendidas pela autora como um bem humano, pode ser alcançado por meio da premeditação lógica sobre as possíveis consequências decorrentes de cada ação. Por isto, Tomás compreende que

a virtude humana torna bom o ato humano e o agente que o pratica, o que é próprio da justiça. Pois, os atos humanos são bons por se sujeitarem à regra da razão, que os retifica. Por onde, a justiça, retificando as ações humanas, é claro que as torna boas. E, como diz Túlio, por causa da sua justiça é que certos homens se chamam bons. Por onde, como diz no mesmo lugar, nela é máximo o esplendor da virtude (Tomás, ST, II-II, Q 58, A 3, resp.).

Assim, a virtude da justiça tem precedência sobre todas as virtudes desejáveis à natureza humana, pois somente ela se manifesta como um querer capaz de animar a razão em sua busca incessante pela compreensão do mundo, do homem e da sua relação com o próximo. Dito isto, "[...] só podemos antecipar os fins e o sentido objetivo das [...] inclinações e, assim, abrir a esfera de ações e fins devidos, isto é, a esfera ética, à luz do intelecto" (González 2016: 20, grifos da autora, tradução nossa). Sendo a luz projetada pelo intelecto, a claridade imposta pela razão, a referência do homem ante o terreno da vida prática e os seus desafios, a justiça para Tomás de Aquino deve ser entendida como o resultado dessa busca constante e interminável do indivíduo pela sua reta conduta, a qual, antecipando racionalmente o resultado de qualquer ação, projeta sobre elas a luz da razão com o intuito de que nem o próximo, nem ele mesmo venha a sofrer com as consequências daninhas dos seus atos irrefletidos. De modo ainda mais objetivo é possível afirmar que, “[a justiça na visão de Tomás é entendida como uma] vontade 
constante e perpétua de dar a cada um o que lhe pertence [...]" (Cruz 2005: 130). O ser humano, ao desviar-se da normativa imposta pela própria racionalidade que o caracteriza como ser pensante e praticar uma ação injusta, torna-se responsável por originar um estado de desequilíbrio inconveniente à desejada harmonia social.

\section{2. $A$ restituição}

A justiça comutativa é um meio de regulamentação das relações

$\mathcal{A}_{\text {sociais, pois, se numa relação de câmbio entre dois indivíduos }}$ a justiça é ferida, então uma discordância é criada em função desse ato $(C f$. Tratado sobre justiça: ST, II-II, Q 57-122). Ora, esse desacordo consiste no fato de que um estado de igualdade, anteriormente existente entre aqueles indivíduos, foi desconfigurado. A injustiça comutativa é o resultado de uma desproporção criada entre dois sujeitos -como, por exemplo, num negócio onde apenas um dos negociantes se beneficia.

Para esses casos em que um estado de proporcionalidade entre dois indivíduos é danificado, determinados expedientes visam solucionar ou, ao menos, amenizar os danos produzidos. A restituição é um recurso que possibilita o restabelecimento daquela condição anterior que foi perdida, a saber: o estado de justiça. Assim sendo, Tomás de Aquino assegura que "restituir não é senão estabelecer outra vez alguém na posse ou no domínio da sua coisa" (Tomás, ST, II-II, Q 62, A 1, resp.). Restituir é uma forma de oportunizar o restabelecimento de um estado de justiça perdido e, consequentemente, a harmonia social.

$\mathrm{Na}$ tentativa de clarificar a função da restituição dentro do universo da justiça, Tomás de Aquino, no Artigo $1^{\circ}$ da Questão 62 da Secunda Secundae, contrapõe algumas ideias consideradas equívocas. O filósofo inicia afirmando que "a restituição opõem-se ao furto. Ora, o furto da coisa alheia é um ato de injustiça, na comutação. Logo, a restituição dela é um ato de justiça reguladora da comutação" (Tomás, ST, II-II, Q 62, A 1, s. c.). Restituir, para Tomás, é um imperativo que emana da consciência dos benefícios e vantagens que a justiça pode conceder à vida em sociedade. Assim, sempre que um estado de justiça, um estado de igualdade entre dois sujeitos é abalado por algum tipo de injustiça, então a restituição aparece como a oportunidade de restabelecimento daquela condição perdida. Nas palavras de Culleton (2017: 249): "Para o Aquinate, remediar o dano sofrido por aquele de quem se tirou algo injustamente (62.6 ad 3), isto é, a restituição, 'é um ato de justiça' (64. 8)". O pensamento de Tomás manifesta a convicção aristotélica da necessidade de proporcionalidade que impera dentro da justiça 
comutativa:"[...] O justo é [um estado] intermediário entre uma espécie de ganho e uma espécie de perda, a saber, os que são involuntários. Consiste em ter uma quantidade igual antes e depois da transação" (Aristóteles, ENV 4, 1132 b 18-20); e, sendo o furto um ato de injustiça comutativa, a restituição torna-se indispensável para que a justiça seja restaurada. Segundo o entendimento de Culleton,

a justiça comutativa se baseia no necessário respeito pela igualdade em transações ou contratos, de tal forma que nenhuma das partes esteja em uma posição pior do que a outra depois que a transação é realizada. Como consequência, a justiça comutativa corresponde a um "raciocínio aritmético", segundo o qual as partes devem trocar mercadorias equivalentes. Neste tipo de justiça, o princípio que rege seria "dar a cada pessoa o que é seu" (Culleton 2017: 252).

Essa herança aristotélica, cuja percepção de que a razão com sua lógica matemática inequívoca no terreno dos valores quantitativos impõe a necessidade de igualdade entre as partes envolvidas em uma transação, é marca indelével no pensamento de Tomás de Aquino. De modo que este filósofo considera a restituição como um imperativo de justiça, já que de uma forma ou de outra esta última foi violada pela irreflexão. Deste modo, entende-se que,

[...] na restituição, considera-se a igualdade da justiça fundada na compensação de uma coisa com outra, o que pertence à justiça comutativa. Portanto, a restituição é um ato de justiça comutativa, isto é, quando a coisa de um é possuída por outro, quer, por vontade deste, como no mútuo ou no depósito, quer, contra a vontade, como no roubo ou no furto (Tomás, ST, II-II, Q 62, A 1, resp.).

Restituir é compensar uma injustiça perpetrada; por exemplo, através do furto. Logo, torna-se necessária por duas razões: I) porque algo foi subtraído de alguém e acrescentado a outro de forma indevida, causando um desequilíbrio; II) porque alguém feriu o seu próprio senso de justiça e, com isso, feriu a própria racionalidade que o define como ser humano. Nesse caso, a restituição deve ser analisada também sob duas óticas: I) deve compensar a injustiça comutativa praticada; e, além disso, II) deve possibilitar o restabelecimento na consciência do agente dessa injustiça aquele estado anterior ao ato do furto, ou seja, sua própria racionalidade em premeditar as consequências das suas ações e a sua própria dignidade como ser pertencente a uma coletividade. 
O Artigo $2^{\circ}$ da Suma trata sobre Se é necessário, para a salvação, fazer-se a restituição do que foi tirado injustamente a outrem. Nele, o filósofo contesta algumas opiniões contrárias à necessidade da restituição para a "salvação da alma". Salienta que "não é remetido o pecado se não for restituído o que foi injustamente tirado” (Agostinho apud Tomás, ST, II-II, Q 62, A 2, s. c.). Nesta afirmação, destaca-se a ideia de que a restituição prima, também, pela retomada de um estado de consciência perdido pelo agente do delito. Essa busca por um restabelecimento de um "estado de consciência perdido" pode, muito bem, ser aproximada à afirmação de que se deve restituir para se salvar. Corrobora com essa visão a seguinte declaração: “Ora, [ao] observar a justiça sendo de necessidade para a salvação, é consequente que seja de tal necessidade restituir o que foi injustamente tirado" (Tomás, ST, II-II, Q 62, A 2, resp.). O filósofo enfatiza que a consecução da justiça é um imperativo para a salvação da alma, do que se pode entender que a justiça é tida como algo maior do que uma simples prática necessária à vida em sociedade; restituir é também uma maneira de restabelecer no delinquente sua condição de dignidade anterior. Portanto, somente através da restituição são restabelecidas ao mesmo tempo a satisfação no injustiçado e a condição prévia do autor da injustiça.

O Artigo $3^{\circ}$ trata sobre Se basta restituir simplesmente o que foi injustamente tirado a outrem. Tomás inicia a exposição dos seus argumentos insistindo na ideia de que

[...] a restituição reduz à igualdade o que, tendo tirado a alguém, causou uma desigualdade. Ora, quem restituiu simplesmente o que tirou restabelece a igualdade. Logo, só está obrigado a restituir tanto quanto tirou (Tomás, ST, II-II, Q 62, A 3, s. c.).

De modo a salientar a importância da restituição, o filósofo reitera a sua obrigatoriedade; apesar disso, considera que

dois casos devemos considerar, no ato pelo qual nos apoderamos injustamente da coisa alheia. Uma é a desigualdade real, que às vezes, não implica injustiça, como no mútuo. Outra é a culpa da injustiça, que pode coexistir com a igualdade real; assim, como quando queremos aplicar a violência, mas, sem o conseguir (Tomás, ST, II-II, Q 62, A 3, resp.).

Tomás explica que pode haver injustiça mesmo não havendo uma desigualdade entre pares, o que não exime do sentimento de culpa o sujeito cujo empreendimento falhou. Sendo assim, Tomás (ST, II-II, Q 62, A 3, resp.) entende que, havendo culpa, há necessidade de pena, pois a finalidade 
desta é, unicamente, "emendar" o delinquente (Tomás, ST, II-II, Q 62, A 3, ad. 3), aliviando o seu sentimento de culpa.

No Artigo $4^{\circ}$, que versa sobre Se devemos restituir o que não tiramos injustamente a outrem, o filósofo insiste na ideia de que, em lato sensu, a restituição aplica-se como compensação de uma desigualdade. Com isto, Tomás (ST, II-II, Q 62, A 4, s. c.) entende que " [...] não haveria igualdade se restituíssemos o que não tiramos. Logo, não é justo [restituir quando não se tirou nada injustamente]". Portanto, se está obrigado a restituir sempre que se tenha causado algum dano a alguém.

Apesar disto, entende que uma pessoa pode ser danificada de duas formas: naquilo que já possuía e naquilo que, provavelmente, chegaria a possuir (Tomás, ST, II-II, Q 62, A 4, resp.). A reparação da primeira requer a restituição integral do bem; já no caso da segunda, declara que

[...] não devemos reparar por uma compensação igual. Porque é menos ter uma coisa virtualmente, que em ato. Ora, quem está em via de alcançar alguma coisa, tem-na só virtual ou potencialmente. Portanto, se lhe restituíssemos de modo a lhe fazer possuí-la em ato, restituiríamos que lhe tiramos, não simplesmente, mas, multiplicadamente, o que a restituição não exige, como dissemos. Estamos, porém, obrigados a dar alguma compensação, conforme a condição das pessoas e dos negócios (Tomás, ST, II-II, Q 62, A 4, resp.).

Com essa distinção, o filósofo caracteriza o tipo de compensação que se deve quando alguém sofre danos em algo que ainda não tenha, mas que possivelmente viria a ter se não tivesse sido prejudicado, como num plantio em que ainda não obteve colheita alguma. Inclusive nesses casos de bens em potencial, se está obrigado a restituir proporcionalmente ao estado da posse, levando-se sempre em consideração o fato de que possuir algo em potencial não é o mesmo que possuir em ato.

Já o Artigo $5^{\circ}$ articula sobre Se devemos sempre restituir aquele de quem recebemos alguma coisa. Por mais que a filosofia tomista seja extremamente rigorosa quanto à obrigatoriedade de compensação em casos de injustiça comutativa, nesse artigo, o filósofo considera algumas situações onde a restituição deve ser pontualmente avaliada. No caso de uma coisa que se deva restituir a alguém, mas que devido à mesma restituição essa poderia ser-lhe prejudicial, Tomás adverte que,

[nesse caso,] não se lhe deve então restituir, porque a restituição se ordena à utilidade daquele a quem é feita; pois, tudo o que possuímos deve nos ser de alguma utilidade. Contudo, o detentor da coisa alheia não deve apropriar-se dela, mas, guardá-la para a restituir em tempo oportuno, ou 
entregar para ser conservada em outra parte, de maneira mais eficaz (Tomás, ST, II-II, Q 62, A 5, ad. 1).

Como restituir é um ato de justiça comutativa, o qual, por sua vez, visa à consecução de um estado de equidade perdido, de modo algum a restituição pode ser regulamentada por um automatismo inconsequente, mas sim deve ser guiado através da premeditação das suas últimas consequências.

Outro caso apresentado pelo filósofo nesse mesmo artigo trata sobre a restituição nos casos em que a pessoa a quem se deve tenha morrido, ou seja desconhecida; nesses casos, Tomás (ST, II-II, Q 62, A 5, ad. 3) infere que

[...] devemos [restituir] na medida do possível, por exemplo, dando esmolas pela sua salvação, quer esteja morto, quer esteja vivo; mas, depois de feita a procura diligente dessa pessoa a quem devemos restituir.

Assim sendo, o devedor não é isentado de fazer a devida restituição e a sua oportunidade de restabelecer-se no estado de consciência e dignidade perdidos não lhe é cerceada.

Em outra consideração, ainda, Tomás de Aquino afirma que

[...] não devemos recompensar nosso benfeitor com o bem alheio, o que se daria se restituíssemos a um o que devemos a outro. Salvo em caso de extrema necessidade, em que poderíamos e deveríamos até mesmo tirar o alheio para socorrer um pai (Tomás, ST, II-II, Q 62, A 5, ad. 4).

Quer dizer, jamais se pode restituir alguém com aquilo que pertença a outrem. Contudo, há casos de extrema necessidade em que o filósofo cogita essa possibilidade, como quando para socorrer um pai ou outra pessoa a quem se deva muitíssimo e que, apesar dessa urgência, a restituição a esse terceiro deverá ser efetuada. O último caso tratado nesse mesmo artigo contrapõe a ideia de que é inútil restituir aquilo que venha a parar novamente em mãos do próprio restituidor, como, por exemplo, um administrador que desviou fundos da sua própria empresa. Tomás (ST, II-II, Q 62, A 5, ad. 5) insiste na ideia de que o que se deve tem de ser restituído e, mesmo no caso em que a restituição volte para as mãos do próprio restituidor, deve-se executá-la com o cuidado de que chegue às instâncias superiores; ao acrescenta: juntamente à restituição, o delinquente deve se abster do ânimo que o levou a delinqüir, de modo que não reincida no mesmo delito (Tomás, ST, II-II, Q 62, A 5, ad. 5).

No Artigo $6^{\circ}$, versando sobre Se quem se apoderou da coisa alheia está sempre obrigado a restituí-la, o filósofo apresenta duas considerações a serem 
feitas com relação a quem se apoderou de coisa alheia: "[...] a coisa mesma de que se apoderou e o ato de apoderamento" (Tomás, ST, II-II, Q 62, A 6, resp., grifos nossos). Quanto à coisa apoderada, Tomás afirma que

[...] quem dela se apossou está obrigado a restituí-la enquanto a tiver em seu poder; porque quem tem mais do que aquilo que lhe pertence, deve privar-se disso e dá-lo a quem tem falta, conforme a razão formal da justiça comutativa (Tomás, ST, II-II, Q 62, A 6, resp.).

Conforme o filósofo, o apoderar-se indevidamente de alguma coisa incorre na obrigatoriedade da restituição, pois feriu a razão que impõe a justiça comutativa; já o ato propriamente dito do apoderamento merece uma análise mais aprofundada.

Pois, assim como quem feriu a outrem está obrigado a dar uma reparação ao que sofreu a injúria, embora nenhum proveito do ato tire o autor, assim também quem furta ou rouba está obrigado a reparar o dano causado, embora nenhum proveito conserve do seu ato; e, além disso, deve ser punido, por causa da injustiça cometida (Tomás, ST, II-II, Q 62, A 6, resp.).

Essa obrigatoriedade de reparar não só a coisa a qual se privou alguém de modo injusto, mas também a ação praticada, é tratada com tamanha relevância que ambas são consideradas como injustiças e, portanto, requerem a devida restituição. E acrescenta:

[Também] está obrigado a restituir o que recebeu, não só considerando-se a coisa em si mesma, mas também levando-se em conta o ato de tê-la recebido, mesmo que já a tenha perdido. Pois, está obrigado a recompensar quem the prestou o serviço; o que não se dará, se este vier a ser prejudicado (Tomás, ST, II-II, Q 62, A 6, resp.).

Segundo Tomás, não se deve só restituir a coisa recebida -como num empréstimo-, mas, também, considerar o uso que se fez dessa coisa, ou o desgaste que teve. Outra abordagem, ainda, diz respeito ao depósito. O depósito difere do empréstimo em vários pontos, pois, contrário ao empréstimo que é útil ao recebedor, o depósito é uma prestação de serviço por parte de quem o recebe, já que não lhe é favorável. Justamente por esse desinteresse da parte de quem fica com a posse do bem em depósito, Tomás (ST, II-II, Q 62, A 6 , resp.) afirma que, "se lha subtraírem, sem sua culpa, não está obrigado a restituí-la. Diferente porém seria o caso se, por grande culpa sua, perdesse o depósito". Com isto, pode-se entender que, nos casos de depósito, não há 
obrigatoriedade de restituição desde que o bem não tenha sido extraviado por culpa ou negligência de quem deveria tê-lo conservado.

Já no Artigo $7^{\circ}$, Se quem não tomou o alheio está obrigado a restituir, o filósofo complementa essas prescrições dizendo que, está obrigado a restituir, "[...] todo aquele que é causa de uma apropriação injusta [...]" (Tomás, ST, II-II, Q 62, A 7, resp.). Portanto, está obrigado à restituição todo aquele que, "[por] mandado, conselho, consentimento, elogio, auxílios, participação, silêncio, falta de oposição, falta de manifestação" (Tomás, ST, II-II, Q 62, A 7, resp.), tenha sido causa confirmada de apropriação injusta. Desses nove casos, os cinco primeiros obrigam à restituição:

Primeiro, o mandado, porque quem manda é quem principalmente move e, por isso, está principalmente obrigado à restituição. Segundo, o consentimento naquilo sem que o roubo não podia ter sido feito. Terceiro, o auxílio, quando alguém asilou o ladrão e lhe prestou ajuda. Quarto, a participação, quando tem parte no crime do latrocínio e na presa. Quinto está obrigado a restituir aquele que não obstou ao roubo, devendo obstá-lo; assim, os chefes, que estão obrigados a distribuir a justiça na terra, estão obrigados a restituir se aumentam, por culpa deles, os ladrões; porque os impostos que os chefes recebem são estipêndios, que recebem para que façam cumprir-se a justiça na terra (Tomás, ST, II-II, Q 62, A 7, resp.).

Chama-se a atenção para o quinto caso, o qual trata daqueles que, tendo por obrigação o dever de obstar um ato criminoso, não o faz. Com isto, o filósofo censura os responsáveis por venderem ao povo a ideia de "segurança" e de "justiça”", mas que não a põem em prática; esses se tornam delinqüentes por receberem altos estipêndios por aquilo que, justamente, não fazem.

Finalmente, no Artigo $8^{\circ}$, Se estamos obrigados a restituir imediatamente ou se, ao invés, podemos licitamente diferir a restituição, é onde o filósofo exige a imediatividade da restituição como um princípio de justiça. Tomando o apoderar-se do alheio como pressuposto de injustiça,Tomás (ST, II-II, Q 62, A 8, resp.) infere que "[...] detê-lo [também é injusto]". Logo, tão injusto quanto a ação cometida é permanecer com o bem adquirido ilegitimamente. $\mathrm{O}$ filósofo insiste que o ato de injustiça cometido deve ser seguido da imediata restituição devida: desde que se possa ser feita. Em caso de impedimento, consente a possibilidade de "[se] pedir uma dilação a quem pode permitir o uso da coisa" (Tomás, ST, II-II, Q 62, A 8, resp.). Apenas nesse caso, o dono da coisa, ou um "entendido" como chama -o juiz-, tem o direito de conceder uma ilação, o que não proscreve a restituição. 


\section{Considerações finais}

É significativo o tratamento que o filósofo dá, ao abordar a restilosofia tomista trata da justiça como virtude fundamental e diretriz da razão: sentido esse que na Modernidade é desconstruído com o advento do racionalismo e a consequente identificação da "verdade" como postulado científico -postulado esse que, após novas descobertas científicas, deixa de representar a "verdade" que representava-. Contudo, o que traz perplexidade e estimula a uma compreensão de mundo não como verdade postulada, mas como perpétua busca pela correção, é a relação que Tomás de Aquino permite que se faça entre a necessidade racional da justiça para a vida em sociedade e o sentimento de culpa que o desvio da irreflexão produz na consciência daquele que infringe o seu próprio imperativo de justiça. Do modo como se aproximou ambos os termos ao longo do texto, foi possível inferir que, devido ao senso de justiça ser oriundo da razão, um ato de injustiça deixa uma marca indelével na sociedade: a desarmonia; e na consciência do infrator: o sentimento de culpa. Matematicamente, a primeira requer uma compensação à injustiça cometida, seja pela coisa que se apropriou, ou pelo ato através do qual a injustiça foi perpetrada ou, quem sabe, somente empreendida; a segunda demanda algo de maior complexidade: restituir um estado de racionalidade à consciência daquele sujeito que infringiu a sua maior característica como ser racional: a razão; mas, também, a sua dignidade frente à sociedade. Portanto, ressalta-se a ênfase que o filósofo dá em dirimir, por meio da restituição, não só a injustiça praticada, mas o sentimento de culpa na consciência do próprio delinquente.

Por fim, percebeu-se que na grande maioria dos artigos da Questão 62 da Secunda Secundae, da Suma teológica, Tomás de Aquino insiste na ideia de que toda ação que cause danos a outrem, em ato ou em possibilidade, constitui uma ação de injustiça comutativa e, portanto, implica na obrigatoriedade imediata da restituição. De modo que restituir é um meio necessário para restabelecer o equilíbrio social e manter a consciência sã naqueles indivíduos que compõem o corpo social na finalidade de ajuda mútua.

\section{REFERÊNCIAS}

Aristóteles (EN), Ética a Nicômaco, in L. Vallandro e G. Bornheim (1979) (trads.), Aristóteles (São Paulo:Victor Civita, v. 2, 45-236).

Cruz, J. (2005), "Direito e o sempre atual Santo Tomás de Aquino”, Revista de Cultura Teológica, 13, (53): 121-134. Disponível em: <https://revistas.pucsp.br/index.

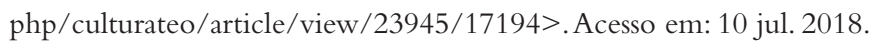


Culleton, A. (2017), “A restituição como dever de justiça em Tomás de Mercado", Revista Filosofia Unisinos, 18, (3): 247-252. Disponível em: <http://revistas.unisinos. br/index.php/filosofia/article/viewFile/fsu.2017.183.16/60746110>. Acesso em: 19 nov. 2018.

González, A. M. (2016), "Natural Law as a Limiting Concept: a Reading of Thomas Aquinas", in González (2016) (ed.), Contemporary Perspectives on Natural Law: Natural Law as a Limiting Concept (New York: Routledge, 11-28).

González, A. M. (2016) (ed.), Contemporary Perspectives on Natural Law: Natural Law as a Limiting Concept (New York: Routledge).

Thomae de Aquino, Sententia libri Ethicorum, Ed. Leonina (1969), vol. 47. 1. (Roma: Sancta Sabina). Disponível em: <https://gallica.bnf.fr/ark:/12148/bpt6k9498r.r>. Acesso em: 16 nov. 2018.

Thomae de Aquino (ST), Summe Theologice. Opera omnia iussu impensaque Leonis XIII P. M. edita (1888-1897), vol. IV-IX, (Roma: Polyglotta). Disponível em: < https://archive.org/details/operaomniaiussui09thom/page/n5>. Acesso em: 16 nov. 2018.

Thomae de Aquino (ST), Suma teológica, trad.Alexandre Correia (Porto Alegre: Livraria Sulina Editora, 1980)

Vallandro, L. e Bornheim, G. (1979) (trads.), Aristóteles (São Paulo:Victor Civita).

Recebido: 09-01-2019; aceito: 01-10-2019 